\title{
Article \\ Portable near Infrared Spectroscopy as a Tool for Fresh Tomato Quality Control Analysis in the Field
}

\author{
Karla R. Borba ${ }^{1, *(\mathbb{D})}$, Didem P. Aykas ${ }^{2,3} \mathbb{D}$, Maria I. Milani ${ }^{4}$, Luiz A. Colnago ${ }^{5} \mathbb{D}$, Marcos D. Ferreira ${ }^{5} \mathbb{D}$ \\ and Luis E. Rodriguez-Saona ${ }^{2, *}$
}

1 Department of Food and Nutrition, School of Pharmaceutical Sciences, São Paulo State University-UNESP, Araraquara-Jaú, Km 1, Araraquara, SP 14801-902, Brazil

2 Department of Food Science and Technology, The Ohio State University, 100 Parker Food Science and Technology Building, 2015 Fyffe Road, Columbus, OH 43210, USA; aykas.1@osu.edu

3 Department of Food Engineering, Faculty of Engineering, Adnan Menderes University, Aydin 09010, Turkey

4 Department of Analytical Chemistry, Institute of Chemistry, UNESP-São Paulo State University, 55 Prof. Francisco Degni Street, Araraquara, SP 14800-900, Brazil; mariaizabelmilani91@gmail.com

5 Embrapa Instrumentation, XV de Novembro 1452, São Carlos, SP 13561-206, Brazil; luiz.colnago@embrapa.br (L.A.C.); marcos.david@embrapa.br (M.D.F.)

* Correspondence: borbakr@gmail.com (K.R.B.); rodriguez-saona.1@osu.edu (L.E.R.-S.); Tel.: +1-614-292-3339 (L.E.R.-S.)

check for updates

Citation: Borba, K.R.; Aykas, D.P.; Milani, M.I.; Colnago, L.A.; Ferreira, M.D.; Rodriguez-Saona, L.E. Portable near Infrared Spectroscopy as a Tool for Fresh Tomato Quality Control Analysis in the Field. Appl. Sci. 2021, 11, 3209. https://doi.org/ 10.3390/app11073209

Academic Editors: David Ian Ellis and Howbeer Muhamadali

Received: 16 March 2021

Accepted: 1 April 2021

Published: 2 April 2021

Publisher's Note: MDPI stays neutral with regard to jurisdictional claims in published maps and institutional affiliations.

Copyright: (c) 2021 by the authors. Licensee MDPI, Basel, Switzerland. This article is an open access article distributed under the terms and conditions of the Creative Commons Attribution (CC BY) license (https:// creativecommons.org/licenses/by/ $4.0 /)$.

\begin{abstract}
Portable spectrometers are promising tools that can be an alternative way, for various purposes, of analyzing food quality, such as monitoring in a few seconds the internal quality during fruit ripening in the field. A portable/handheld (palm-sized) near-infrared (NIR) spectrometer (Neospectra, Si-ware) with spectral range of 1295-2611 nm, equipped with a micro-electro-mechanical system (MEMs), was used to develop prediction models to evaluate tomato quality attributes nondestructively. Soluble solid content (SSC), fructose, glucose, titratable acidity (TA), ascorbic, and citric acid contents of different types of fresh tomatoes were analyzed with standard methods, and those values were correlated to spectral data by partial least squares regression (PLSR). Fresh tomato samples were obtained in 2018 and 2019 crops in commercial production, and four fruit types were evaluated: Roma, round, grape, and cherry tomatoes. The large variation in tomato types and having the fruits from distinct years resulted in a wide range in quality parameters enabling robust PLSR models. Results showed accurate prediction and good correlation $\left(R_{\text {pred }}\right)$ for SSC $=0.87$, glucose $=0.83$, fructose $=0.87$, ascorbic acid $=0.81$, and citric acid $=0.86$. Our results support the assertion that a handheld NIR spectrometer has a high potential to simultaneously determine several quality attributes of different types of tomatoes in a practical and fast way.
\end{abstract}

Keywords: infrared spectroscopy; handheld spectrometer; fresh tomato quality; partial least squares (PLS); field production

\section{Introduction}

The great popularity of the tomato is mainly related to the fact that it can be eaten in multiple fresh or processed forms, being the second most important vegetable crop produce worldwide. In 2019, global tomato production was approximately 197 million tons [1], with $75 \%$ for the fresh market and $25 \%$ for processing. The USA is the world's third-largest tomato producer. California and Florida are the biggest producers representing two-thirds of the USA total production area [2].

For a long time, tomato breeding programs have focused on crop yield, fruit shape, and shelf-life [3]. However, over the past 30 years, tomato breeders aimed at the development of high-quality tomato to supply customer demands for fresh fruits with good visual appearance, higher organoleptic and nutritional characteristics [3,4]. Therefore, to guarantee the internal quality of the fruit, its titratable acidity, soluble solids, sugars, organic acids, and lycopene contents have to be taken into consideration. The conventional 
techniques used to determine these quality parameters are laborious and time-consuming, determine a single parameter, and some of them require the use of toxic reagents and trained staff to perform the measurement [5].

Non-invasive methods based on physical principles, couple with multivariate analysis, have shown the potential to measure several parameters in a single measurement. Most of these methods are based on vibrational/rotational (infrared), electronic (ultraviolet (UV)-visible), and nuclear magnetic resonance spectroscopies [6]. Among these methods, near-infrared (NIR) spectroscopy from 1000 to $2500 \mathrm{~nm}$ is one of the most popular. NIR absorption is assigned to the overtone or combination bands of the fundamental vibrational and rotational transitions [7]. The NIR spectrum shows broad bands associated with combinations of vibration modes $(\mathrm{O}-\mathrm{H}, \mathrm{N}-\mathrm{H}$, and $\mathrm{C}-\mathrm{H})$, and overtones of molecular vibrations can be used to determine the parameters of concentrations of fruit quality [8].

Handheld NIR sensors (NIRS) have been used to provide non-destructive real-time and in-field information to optimize harvesting times for greater quality during on-tree ripening [9]. Rapid screening and characterization of major quality parameters of tomatoes have been increasing due to spectrometer portability and miniaturization of optical sensor technology. Novel low cost-effective, non-invasive, robust, and faster spectrometers have been developed, becoming the leading instrument for fruit and vegetables quality screening in the field $[10,11]$. Research on the applications of portable NIR systems to determine the quality attributes of fruits and vegetables has increased in the last few years [12-16]. Portable NIR spectrometers have been applied to measure firmness, soluble solid content (SSC), and/or pH in strawberries [17], plums [18], oranges [19,20], tomatoes [21], and bell peppers [22]. Also, handheld spectrometers were successfully applied to evaluate moisture and fat content of fresh olives [23,24] and to classify the maturity stage in avocados [25].

We report on the performance of a novel micro-electro-mechanical systems (MEMS) approach to miniaturize optical, mechanical, and hardware components of large and stationary spectrometers $[9,26]$. MEMS integrates mechanical elements, sensors, actuators, and electronics technologies that enable rotation of miniature gratings, measure spectra at millisecond time resolution, and co-add several scans to one spectrum, generating a good signal-to-noise ratio [27]. By using an extended InGaAs (Indium Gallium Arsenide) detector, the MEMS spectrometer can collect spectra in the long-wavelength NIR region (1350 to $2500 \mathrm{~nm}$ ) which consists of sharper bands associated to combinations or first overtones of the $\mathrm{OH}, \mathrm{CH}$, and $\mathrm{NH}$ modes.

The aim of this study was to develop robust and accurate multivariate prediction models using a MEMS-based handheld NIR spectrometer to determine SSC, sugars, titratable acidity (TA), and organic acids of different types of fresh tomatoes (Roma, round, cherry, and grape) and evaluate its feasibility for in-field application.

\section{Materials and Methods}

\subsection{Samples}

A total of 319 fresh market tomato samples including different types (Roma, round, grape and cherry) and ripening stages (green, breakers, turning, pink, light red, and red), according to the United States Standards for Grades of Fresh Tomatoes [28], were analyzed in this study. Samples were harvested from Florida and California farms during the 2018 and 2019 growing seasons. In 2019, part of the external validation (prediction step) was done in Florida directly in the field.

\subsection{Spectra Acquirement}

The NIR spectrum for each intact tomato sample was collected at room temperature $\left(20 \pm 5{ }^{\circ} \mathrm{C}\right)$ using a portable NIR spectrometer (Neospectra-Module, Si-Ware Systems, Cairo, Egypt) (Figure 1) that is an equipment with an integrated light source and based on a micro-electro-mechanical system spectrometer. Spectra were collected in the 1295-2611 nm range, $16 \mathrm{~cm}^{-1}$ resolution, and $20 \mathrm{~s}$ scan. During the spectra acquisition, samples were placed in a rotating stage and scanned in the equatorial region. The field analyses were 
performed at the Lipman Family farm in Florida, USA, allowing us to test the performance of the NIR device under field conditions. Those spectra were added to the prediction (external validation) dataset.

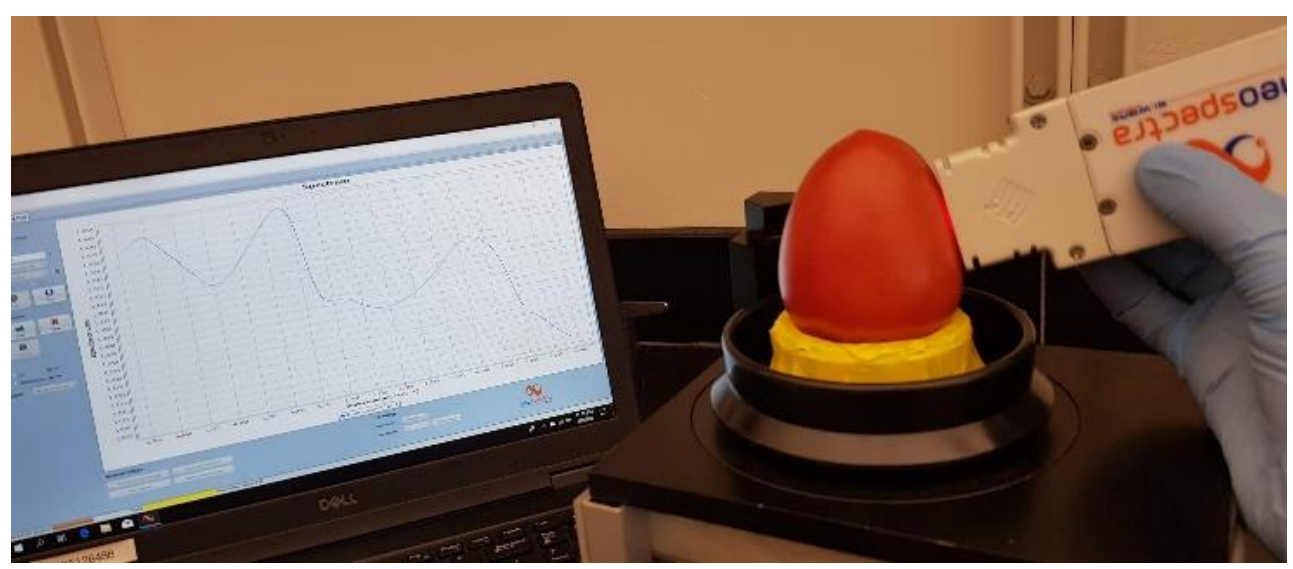

Figure 1. Experimental setup for acquiring the near infrared (NIR) spectrum of equatorial region of a rotating tomato using a handheld NIR spectrometer (Neospectra-Module).

\subsection{Chemical Analysis}

Destructive measurements were performed immediately after the spectral acquisition to determine the quality attributes used as reference values. Roma and round tomatoes were blended by using a laboratory blender (6646 Oster 12 speed blender, Sunbeam Products, Inc., Boca Raton, FL, USA), and grape and cherry types were used a handheld homogenizer (Benchmark Scientific Inc., Sayreville, USA), each tomato was individually blended. Tomato juice samples were extracted to estimate the total soluble solids content (SSC) and titratable acidity (TA). The SSC was determined using a digital refractometer (ATAGO, Bellevue, WA, USA) at $20^{\circ} \mathrm{C}$ with $\pm 0.1 \%, 2 \mathrm{~mL}$ of juice were added into a centrifuge tube and centrifuged for $15 \mathrm{~min}$ at 13,000 rpm. A supernatant aliquot was placed in the refractometer detector and the results were expressed as ${ }^{\circ}$ Brix. TA analysis was performed with an automatic titrator (Easy pH Titrator-Mettler Toledo, Columbus, OH, USA) with $0.5 \mathrm{~mol} \mathrm{~L}^{-1} \mathrm{NaOH}$ and using $2 \mathrm{~g}$ of juice diluted in $40 \mathrm{~mL}$ of ultrapure water.

Glucose and fructose concentrations were quantified using reverse-phase high-performance liquid chromatography (HPLC). Tomato juice aliquots $(1.5 \mathrm{~mL})$ were centrifuged at 13,000 rpm for $15 \mathrm{~min}$ at $25^{\circ} \mathrm{C}$; supernatant $(1 \mathrm{~mL})$ was filtered through $0.45 \mu \mathrm{m}$ pore into the HPLC vials. Filtrated supernatant was injected $(25 \mu \mathrm{L})$ in a Shimadzu UFLC (Ultra Fast Liquid Chromatograph) (Shimadzu, Columbia, MD, USA) equipped with dual LC-6AD, SIL-20AHT auto-sampler, a CTO-20A column oven and RID-10A refractive index detector. A stainless steel Rezex RCM-Monosaccharide Ca+ column (Phenomenex ${ }^{\circledR}$, Torrance, CA, USA) with $300 \times 7.8 \mathrm{~mm}$ dimensions was used to carry out an isocratic separation at $80^{\circ} \mathrm{C}$ with HPLC grade water as the solvent at $1.0 \mathrm{~mL} / \mathrm{min}$ flow rate during $20 \mathrm{~min}$ runs. The concentration of each sugar was determined using a calibration curve that was prepared with standards of glucose and fructose (Fisher Scientific, Fair Lawn, NJ, USA) in a range of concentrations between 1.6 and $25 \mathrm{mg} / \mathrm{mL}$.

Organic acids (ascorbic and citric acid) were determined by reverse-phase high performance liquid chromatography (HPLC). Tomato juice ( $0.5 \mathrm{~g}$ ) was extracted with $4.5 \%$ metaphosphoric acid and $100 \mathrm{mmol} / \mathrm{L}$ tris [2-carboxyethyl] phosphine (TCEP) was added to improve the stability of ascorbic acid [29]. The separation was achieved by using a C18 based Prevail organic acids column $(5 \mu, 150 \times 4.6 \mathrm{~mm})$ (Hichrom, Berkshire, UK) using $\mathrm{pH} 2.2$ ultrapure water running at a flow rate of $0.8 \mathrm{~mL} / \mathrm{min}$. The calibration curve was developed using different concentrations of reagent grade ascorbic acid and citric acid (Fisher Scientific, Hampton, NH, USA) and was used to determine acid concentrations. 
The elution of analytes was monitored at $210 \mathrm{~nm}$ (citric acid) and $245 \mathrm{~nm}$ (ascorbic acid) using a photodiode array detector.

\subsection{Multivariate Analysis}

Partial least squares regression (PLSR) was used to develop tomato quality prediction models using the Pirouette software (Infometrix, Bothell, WA, USA). The NIR spectra were normalized and mean centralization. The second derivative and orthogonal signal correction were applied to correct baseline shifts, decrease noise regions and evidence specific absorption bands. The PLSR models were built by using the reference values as dependent variables and the NIR spectral data as independent variables. To calibrate, validate (cross-validation), and predict (external validation) the PLSR model's data were randomly separated in two sets, $80 \%$ of samples were used in the calibrate and validate (cross-validation) step and the remaining $20 \%$ to predict and validate the performance of models externally. Cross-validation by using leave-one-out algorithm was applied to do an internal validation in each calibration model. In the leave-one-out cross validation approach, each spectrum is dropped from the data set, and the remaining spectra are used for prediction of left-out data point until every spectrum is left-out once. The prediction set consisted of a blend between tomatoes analyzed at the laboratory and samples by which spectra were collected in the field.

Model performances were reported in terms of correlation coefficient of cross validation $\left(r_{v}\right)$, the correlation coefficient of prediction $\left(r_{\text {pred }}\right)$, the standard error of cross validation (SECV), and the standard error of prediction (SEP) that shows the magnitude of error expected when the concentration of the independent/unknown samples are predicted, and number of factors.

\section{Results and Discussion}

\subsection{Reference Values}

Reference compositional average, standard deviation, and ranges obtained for all quality parameters are summarized in Table 1, based on the tomato types. The values were similar to those reported previously in the literature [30]. The wide range in the compositional levels was due to the great diversity of tomato types, cultivar genotypes, maturity index, harvest from different seasons, and growing under different environmental and soil conditions. The composition data showed that grape and cherry tomatoes had higher SSC, sugar, and organic acids levels, similar to reported by Akpolat et al. [30]. These tomatoes are small and have less water content, making them more concentrated, mainly in relation to sugars [31].

Glucose and fructose are the main sugar components in tomatoes with similar concentrations; however, there is a particular advantage with the higher fructose content varieties in terms of fruit quality and consumer preference since fructose provides more sweetness than its isomer glucose [32]. The balance between sugars, acids and aroma volatile compounds are responsible for the final flavour [31,33]. The perception of fruit acidity is due mainly to citric acid level, which is one of the mainly organic acids in tomato. Besides taste, organic acids can be nutritionally important compounds, such as ascorbic acid (or vitamin C). The levels of ascorbic acid found in this work were wide, ranging from 3.8 to $77.9 \mathrm{mg} / 100 \mathrm{~g}$ slightly above than found in similar works [30,34]. The average ascorbic acid content in all 4 tomatoes types was $29.3 \mathrm{mg} 100 \mathrm{~g}^{-1}$; these results are similar to Akpolat et al. [30]. 
Table 1. Values of the quality parameters determined in tomato samples, from 2018 and 2019 growing seasons, using reference methods.

\begin{tabular}{|c|c|c|c|c|c|c|}
\hline Parameters & Tomato Type & $\mathbf{N}$ & Average & SD & Range & CV (\%) \\
\hline \multirow[t]{5}{*}{ Soluble solids ( ${ }^{\circ}$ Brix) } & all & 319 & 5.72 & 1.68 & $2.92-11.22$ & 29.47 \\
\hline & Roma & 106 & 4.45 & 0.82 & $2.92-9.93$ & 11.52 \\
\hline & round & 47 & 4.59 & 0.53 & $3.49-5.95$ & 11.54 \\
\hline & grape & 93 & 6.81 & 1.24 & $4.29-9.36$ & 18.25 \\
\hline & cherry & 73 & 6.91 & 1.8 & $3.96-11.22$ & 26.13 \\
\hline \multirow[t]{5}{*}{ Glucose $\left(g . \mathrm{L}^{-1}\right)$} & all & 319 & 16.61 & 7.37 & $4.68-39.12$ & 44.44 \\
\hline & Roma & 106 & 12.92 & 4.29 & $7.57-32.87$ & 33.18 \\
\hline & round & 47 & 12.06 & 3.31 & $4.68-21.74$ & 27.46 \\
\hline & grape & 93 & 20.66 & 7.14 & 7.94-35.79 & 34.58 \\
\hline & cherry & 73 & 20.26 & 8.34 & $8.65-39.12$ & 40.47 \\
\hline \multirow[t]{5}{*}{ Fructose $\left(\mathrm{g} . \mathrm{L}^{-1}\right)$} & all & 319 & 22.25 & 8.71 & $5.33-47.01$ & 39.17 \\
\hline & Roma & 106 & 16.18 & 4.34 & $10.57-36.04$ & 26.84 \\
\hline & round & 47 & 17.10 & 5.48 & $5.33-42.67$ & 32.05 \\
\hline & grape & 93 & 26.39 & 8.13 & $11.44-45.18$ & 30.83 \\
\hline & cherry & 73 & 28.41 & 8.40 & $15.31-47.01$ & 29.56 \\
\hline \multirow[t]{5}{*}{ TA (g citric acid. $100 \mathrm{~g}^{-1}$ ) } & all & 204 & 0.41 & 0.2 & $0.12-1.40$ & 49.31 \\
\hline & Roma & 84 & 0.40 & 0.21 & $0.13-1.40$ & 51.96 \\
\hline & round & 45 & 0.38 & 0.2 & $0.15-1.29$ & 53.59 \\
\hline & grape & 43 & 0.49 & 0.22 & 0.15-1.09 & 45.68 \\
\hline & cherry & 32 & 0.40 & 0.14 & $0.12-1.77$ & 36.91 \\
\hline \multirow[t]{5}{*}{ Ascorbic acid (mg. $100 \mathrm{~g}^{-1}$ ) } & all & 149 & 29.32 & 14.71 & $3.77-77.91$ & 44.84 \\
\hline & Roma & 63 & 27.58 & 11.42 & $12.09-56.91$ & 41.39 \\
\hline & round & 35 & 24.6 & 9.13 & $11.30-41.65$ & 37.12 \\
\hline & grape & 27 & 33.85 & 22.59 & $3.78-77.91$ & 52.10 \\
\hline & cherry & 24 & 38.83 & 12.32 & $14.70-62.29$ & 31.73 \\
\hline \multirow[t]{5}{*}{ Citric acid (g. $\left.100 \mathrm{~g}^{-1}\right)$} & all & 149 & 0.54 & 0.21 & $0.11-1.10$ & 39.28 \\
\hline & Roma & 63 & 0.54 & 0.22 & $0.11-0.97$ & 41.99 \\
\hline & round & 35 & 0.42 & 0.18 & $0.18-0.99$ & 43.52 \\
\hline & grape & 27 & 0.56 & 0.19 & $0.15-1.10$ & 34.49 \\
\hline & cherry & 24 & 0.64 & 0.14 & $0.42-1.04$ & 21.99 \\
\hline
\end{tabular}

N: number of samples; SD: Standard Deviation; CV: Coefficient of variation; TA: total acidity.

\subsection{Partial Least Squares (PLS) Prediction Models Based on Near Infrared (NIR) Measurements}

Handheld units are valuable tools for field applications to provide real-time information on the phenotypic traits expressed by fruits for breeding selection. Remote sensing and high-performance computing are paving the way for affordable, automated and non-invasive sensors [35]. Most studies employing handheld devices in tomatoes have employed low-cost silicon-based CCD (charge-coupled-device) detectors with operational wavelength ranges limited to the short wave NIR (SWNIR, 780-1400 nm) range. However, the SWNIR does not typically coincide with unique spectral signatures that can be used for adequate quantification of food quality traits, especially for commodities targeting sugars and acids components because their unique absorption bands occur in the longer wavelengths ( $>1400 \mathrm{~nm}$ ) [36]. Thus, prediction of the soluble solids, sugars, and acids of the fresh tomatoes by handheld NIR devices operating in the SWNIR (shortwave near infrared) have shown limited success [4,37-39].

Our study is the first study to report on the use of a on-chip Fourier transform (FT) NIR spectrometers equipped with a MEMS interferometer (1350-2560 nm) and InGaAs detector arrays enabling access to the longer-wave spectral range where critical spectroscopic signatures related to the quality of tomato products can be obtained. Figure 2 shows the NIR spectra of all four tomato types (Roma, round, grape, and cherry) that consist of overtones and combination bands of fundamental vibrations $[7,40,41]$. Two strong NIR 
bands assigned to O-H absorbance are shown between 1923-1960 (first overtone) and $1515-1400 \mathrm{~nm}(\mathrm{O}-\mathrm{H}$ stretching) [42]. The bands from 1350-1428 and 2300-2480 nm can be assigned to combination bands of $\mathrm{C}-\mathrm{H}$, typically from carbohydrates [7]. The weak band close to $1800 \mathrm{~nm}$ has been assigned to the third $\mathrm{C}-\mathrm{H}$ overtone and related to sugar content. In Figure 2, it is also possible to see the spectra pattern variation among the four different tomato types. Two separated groups were clustered, tomatoes with less sugar and more water content (Roma and round) and fruits with high sugar content and less water (grape and cherry). Those groups have distinct spectrum patterns, mainly in the absorption bands related to O-H overtone (around $2000 \mathrm{~nm}$ ), $\mathrm{C}-\mathrm{H}$ third overtone and combinations bands (2500-2272 and around $1800 \mathrm{~nm}$ ) [43]. Those are characteristic regions for water and sugar compounds absorption $[7,41]$.

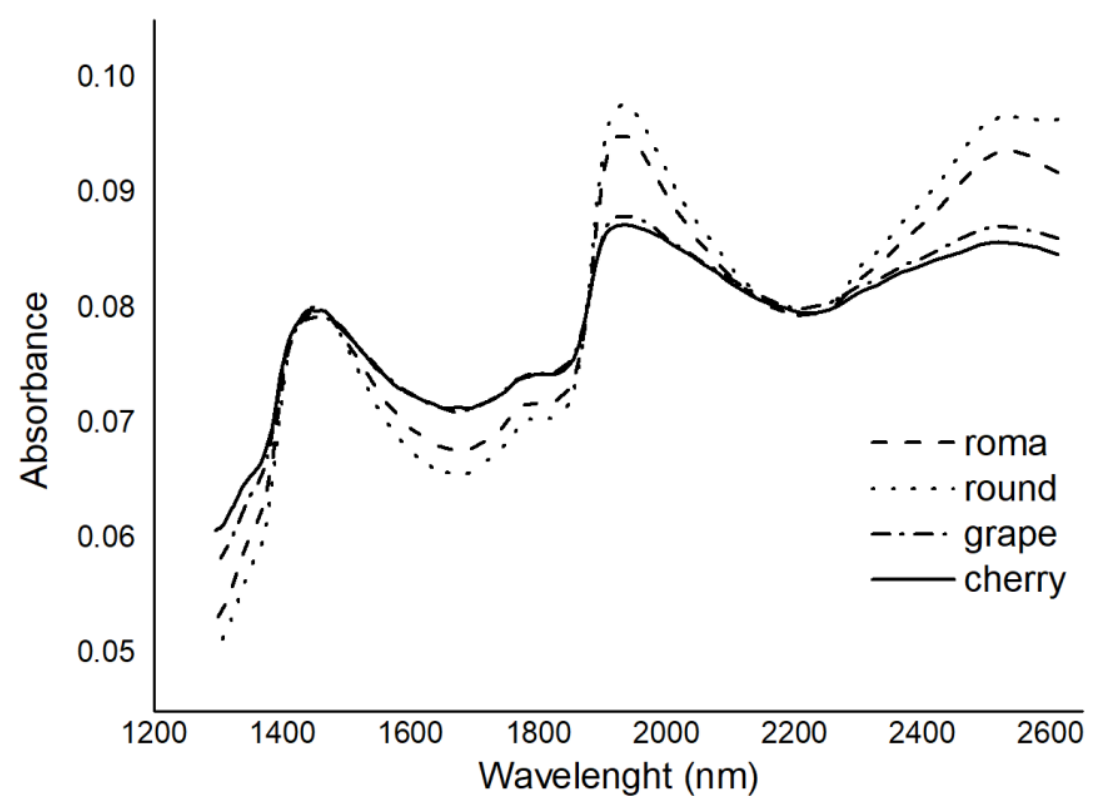

Figure 2. Normalized spectra of different types of tomato (Roma, round, grape, and cherry) collected using a portable NIR infrared (Neospectra-Module).

The absorption bands in the NIR region are complex, with broad and overlapped bands. This overlap can difficult the interpretation and requires multivariate analysis to understand and explain the set of spectra and identify its correlation with parameters of interest [42,44]. Using appropriate chemometric tools, preprocessing, and transformation, these broad bands are especially useful for quantitative analysis. Table 2 shows the statistical performance of the PLS models developed and each transformation used to develop these models. For the development of the PLS prediction models of fructose, glucose, citric, and ascorbic acid, the full spectra (1295-2611 nm) were used. For soluble solids and total acidity prediction models, reduced spectral ranges were used: SSC cherry-grape: 1356-2231 nm; SSC Roma-round: 1374-1930 nm; TA cherry-grape: 1576-2505 nm; TA Roma-round: $1674-2611 \mathrm{~nm}$. 
Table 2. Statistical performance of the partial least squares regression (PLSR) models developed.

\begin{tabular}{|c|c|c|c|c|c|c|c|c|c|}
\hline Parameter & Type of Tomatoes & Preprocessing & $\mathbf{N}$ cal & $\mathbf{F}$ & SECV & $\mathbf{r}_{\mathrm{CV}}$ & $\mathbf{N}$ pred & SEP & $\mathbf{r}_{\text {pre }}$ \\
\hline \multirow{2}{*}{ SSC $\left({ }^{\circ}\right.$ Brix $)$} & Roma-Round & Mean center + Smooth & 152 & 5 & 0.23 & 0.88 & 38 & 0.22 & 0.87 \\
\hline & Cherry-Grape & $(15)+2$ nd deriv (15) & 166 & 6 & 0.64 & 0.89 & 42 & 0.52 & 0.88 \\
\hline Glucose (g. $\left.100 \mathrm{~g}^{-1}\right)$ & All types & Norm + 2nd deriv (15) & 250 & 4 & 3.01 & 0.87 & 58 & 2.91 & 0.83 \\
\hline Fructose (g. $100 \mathrm{~g}^{-1}$ ) & All types & Norm + 2nd deriv (15) & 250 & 5 & 3.48 & 0.87 & 58 & 2.83 & 0.87 \\
\hline \multirow{2}{*}{ TA (g citric acid. $100 \mathrm{~g}^{-1}$ ) } & Roma-Round & Mean center + Smooth & 98 & 6 & 0.03 & 0.87 & 25 & 0.02 & 0.89 \\
\hline & Cherry-Grape & $(21)+2$ nd deriv $(21)$ & 39 & 7 & 0.05 & 0.92 & 10 & 0.04 & 0.94 \\
\hline Ascorbic acid (mg. $100 \mathrm{~g}^{-1}$ ) & All types & Norm + 2ndderiv (15) & 100 & 6 & 3.78 & 0.82 & 46 & 4.09 & 0.81 \\
\hline Citric acid (g. $100 \mathrm{~g}^{-1}$ ) & All types & Norm + 2nd deriv (25) & 100 & 6 & 0.06 & 0.87 & 46 & 0.07 & 0.86 \\
\hline
\end{tabular}

SSC: soluble solid contents; TA: total acidity; $\mathrm{N}$ cal: number of samples in the calibration set; $\mathrm{N}$ pred: number of samples in the prediction set; F: factors; SECV: standard error of cross validation; $r_{v a l}$ : correlation coefficient of cross validation; SEP: standard error of prediction; $\mathrm{r}_{\text {pre: }}$ correlation coefficient of prediction; Norm: normalization; Deriv: derivative; OSC: orthogonal signal correction.

To improve the correlation performances of the SSC and the TA models, separate calibration models were generated for Roma and round (large varieties) and grape and cherry (small varieties) tomatoes. Good prediction performances were obtained for the SSC with correlation coefficients $\left(\mathrm{r}_{\mathrm{cv}}\right)$ of 0.88 and 0.89 and standard error of cross-validation (SECV) of 0.23 and 0.64 for the large (Roma-round) and small (grape-cherry) varieties, respectively (Table 2). The SECV for both SSC models were low when considering the wide range of concentrations ( $3-10{ }^{\circ}$ Brix for the Roma-round varieties and 4.0-11.2 ${ }^{\circ}$ Brix for the grape-cherry varieties). The model performance for SSC was superior to that reported in evaluating the feasibility of a miniaturized NIR spectrometer to determine the quality attributes of San Marzano (large varieties) tomatoes [21], reporting $\mathrm{r}_{\text {pre }}=0.8$ and standard error of prediction values of $0.43^{\circ}$ Brix. Feng et al. [40] used a portable NIR spectrometer (950 to $1650 \mathrm{~nm}$ ) equipped with a fiberoptic probe to evaluate Cherry tomato quality with a narrow soluble solid content ranging from $5.5-7.40^{\circ}$ Brix, with model performances that gave a standard error of prediction of $0.20^{\circ}$ Brix and $R^{2}$ pre $=0.86$.

Good statistical performances were also obtained for the TA models, the $\mathrm{r}_{\mathrm{cv}}$ values were 0.87 and 0.92 , while the SECV values were 0.03 and 0.05 for the large and small varieties, respectively (Table 2). Again, our models performed better than those reported by Castrignanò et al. [21] that reported standard error of prediction of $0.48 \%$ and $\mathrm{R}^{2}$ pre $=0.79$ and showed similar errors to those reported by Wilkerson et al. [45].

The rest of the models, including glucose, fructose, citric, and ascorbic acid, were generated by integrating all the samples (both small and large varieties) into the models. The fructose and glucose models showed similar performances (in terms of $\mathrm{r}_{\mathrm{cv}}$ and SECV), the $r_{\mathrm{cv}}$ values were 0.87 and 0.87 ; also, the SECV values were 3.01 and 3.48 for glucose and fructose models, respectively (Table 2). The ascorbic and citric acid also showed good prediction performance with the $\mathrm{r}_{\mathrm{cV}}$ of 0.87 and 0.82 and SECV of 0.06 and 0.82 for citric and ascorbic acids, respectively (Table 2). The individual acid models (citric and ascorbic) demonstrated the applicability of a portable spectrometer (Neospectra) to make accurate predictions in a few seconds without any sample preparation, with low errors of

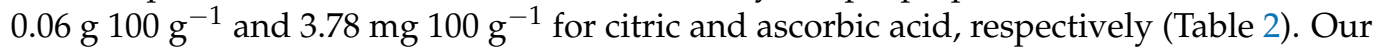
organic acids results were comparable to those obtained in other studies that used mid-IR spectroscopy $[29,44]$.

Correlation plots, besides statistical PLSR model results, are helpful to visualize the relationship between measured and NIR predicted quality parameters levels. Figures 3 and 4 show the correlation plots between reference values and predicted values obtained by using NIR spectra for all quality parameters in both steps (calibration and prediction), and Figures 5 and 6 show the regression vectors of PLSR models. The correlation plots show a high degree of linearity that indicates that the models are able to accurately predict the tomato quality attributes based on the NIR spectral data. The regression vectors information enables identifying the most important absorption bands related to each quality parameter, showing the bands more responsible for the prediction of quality parameter. 
The main responsible bands found were absorption bands around $2000(\mathrm{O}-\mathrm{H}$ absorption region), 1800 (3rd C-H overtone), 1490 (O-H stretch), and $1370 \mathrm{~nm}$ (C-H combinations) are tightly related to absorption of molecules present in quality attributes in tomatoes (carbohydrates, organic acids, and water) [7].
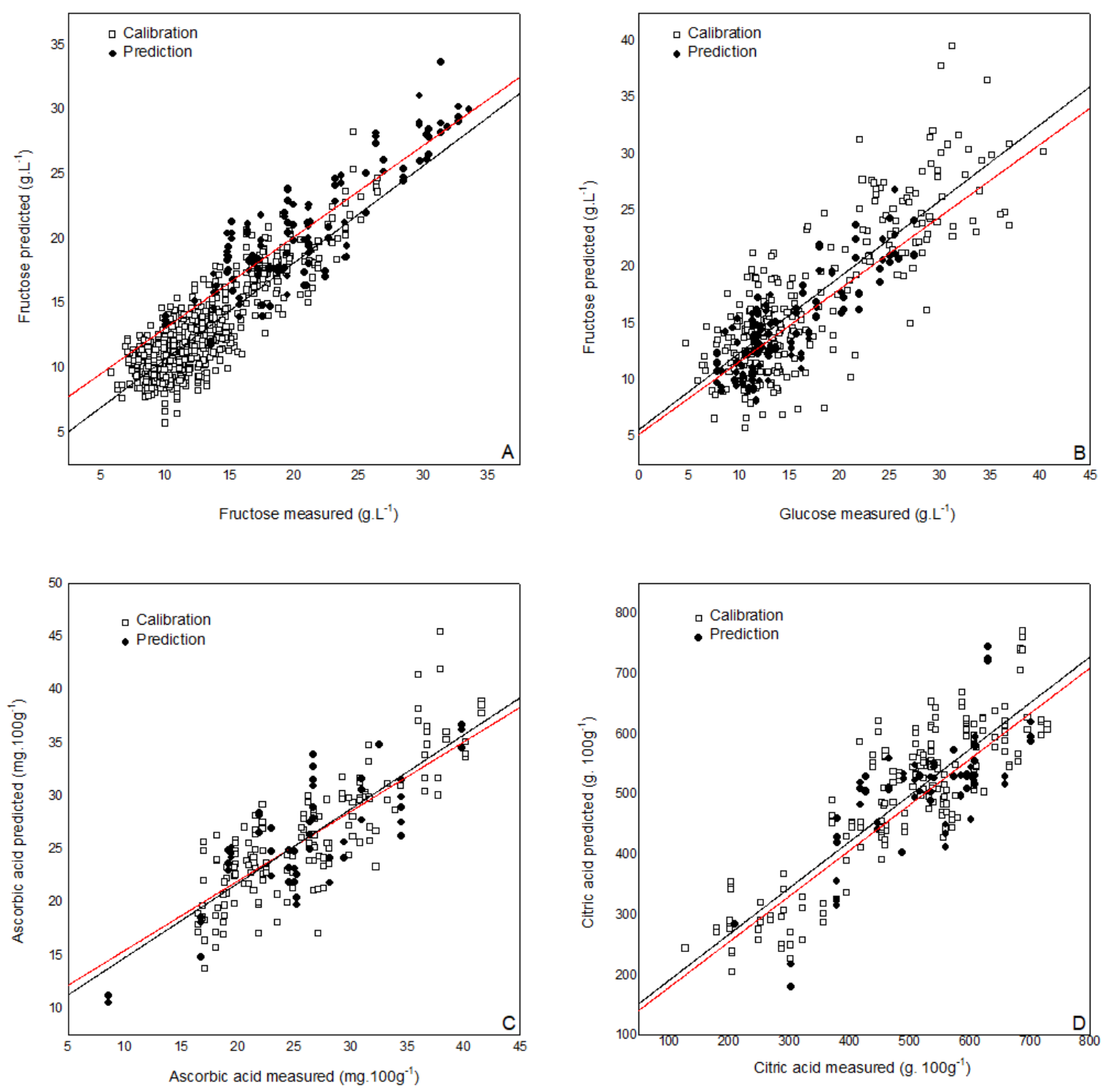

Figure 3. Scatter plot of PLSR models predicted and actual value for fructose (A), glucose (B), ascorbic (C) and citric acid (D). White and black squares represent calibration and validation set samples, respectively. Black regression line: calibration set; red regression line: external validation set. 

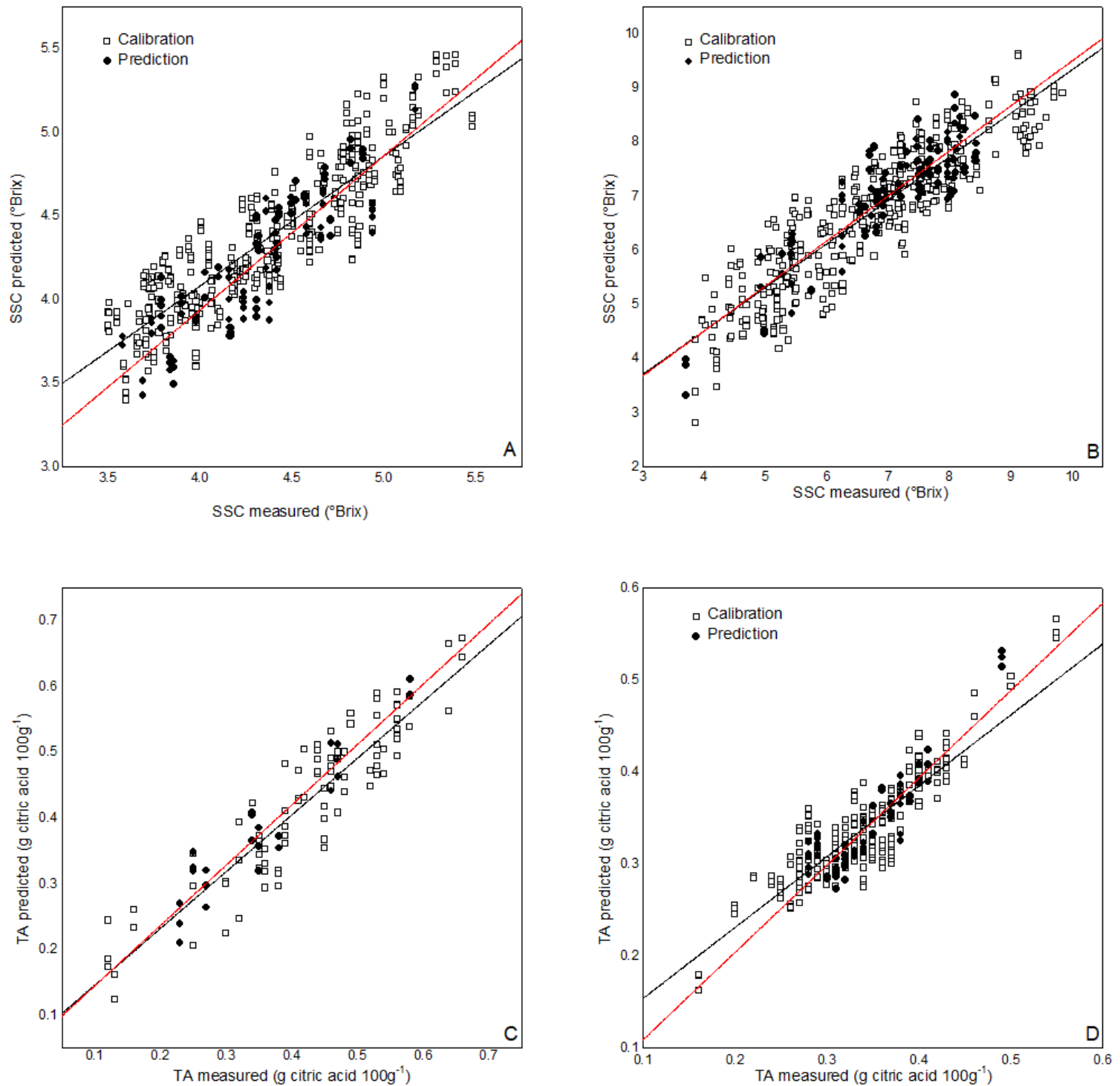

Figure 4. Scatter plot of PLSR models predicted and actual value for SSC, round and roma tomatoes (A) and grape and cherry $(\mathbf{B})$; total acidity for round and roma tomatoes $(\mathbf{C})$ and grape and cherry $(\mathbf{D})$. White and black squares represent calibration and validation set samples, respectively. Black regression line: calibration set; red regression line: external validation set. 

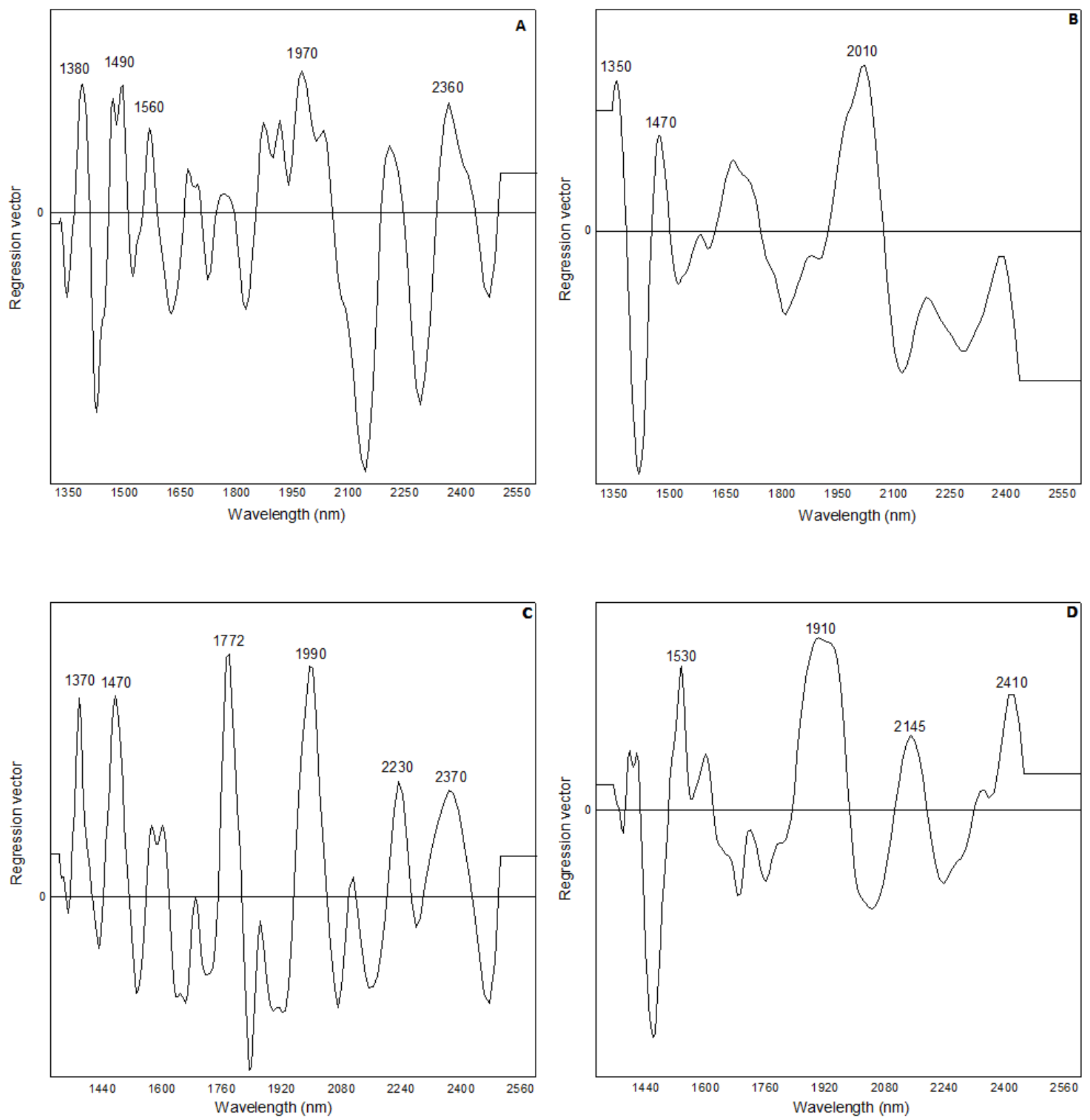

Figure 5. Regression vectors for fructose (A), glucose (B), ascorbic (C) and citric acid (D). 

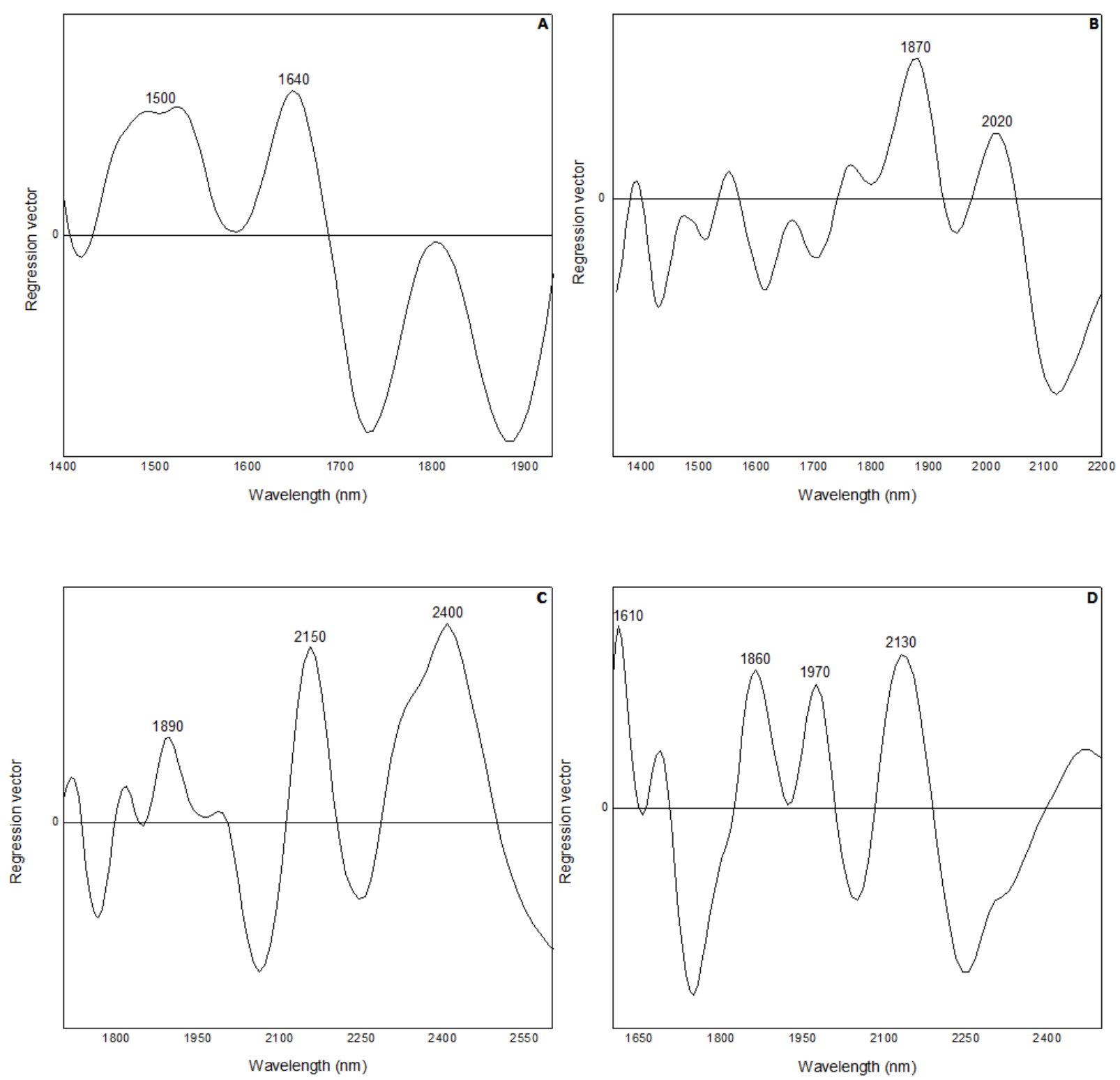

Figure 6. Regression vectors for SSC, round and roma tomatoes (A) and grape and cherry (B); total acidity for round and Roma tomatoes (C) and grape and cherry (D).

\section{Conclusions}

The strong correlation between spectral data and the reference values $\left(\mathrm{r}_{\mathrm{pred}} \geq 0.81\right)$ as well as low standard errors found in this work are evidence of the potential of a portable NIR spectrometer to determine tomato quality parameters. The non-invasive analyses performed in approximately $20 \mathrm{~s}$ show that a NIR portable spectrometer can be a useful tool to help farmers make fast management decisions (for example, about harvest time). We obtained improved model performances by employing a handheld spectrometer equipped with a MEMS-based interferometer and InGaAs detector arrays that takes advantage of the unique spectral information in the long-wave NIR (LWNIR) region, showing improved performance over other commercial handheld devices using the SWNIR region. Furthermore, the handheld device allowed the simultaneous quantification of six quality parameters in different types of tomato using a PLSR algorithm. Furthermore, we obtained good prediction performance of an independent validation set measured in the field without the need to transport the tomatoes to a laboratory. 
Author Contributions: K.R.B.: methodology, formal analysis, data curation, and writing-original draft preparation. D.P.A.: data curation, validation, writing-review and editing. M.I.M.: formal analysis and writing-review and editing. M.D.F.: validation and writing-review and editing. L.A.C.: validation and writing-review and editing. L.E.R.-S.: conceptualization, methodology, data curation, validation, supervision, writing-review and editing. All authors have read and agreed to the published version of the manuscript.

Funding: This research was funded by CAPES institution providing the scholarship, grant number "88881.187998/2018-01" and "CNPq-Research Productivity Fellowship", grant "309043/2016-6 and $302866 / 2017-5 "$.

Institutional Review Board Statement: Not applicable.

Informed Consent Statement: Not applicable.

Data Availability Statement: Not applicable.

Acknowledgments: The authors would like to thank Lipman Family Farms (Florida, US) for providing tomato samples.

Conflicts of Interest: Authors declare that they have no conflict of interest. This article does not contain any studies with human or animal subjects.

\section{References}

1. FAO. Food and Agriculture Organization of the United Nations. Available online: http://www.fao.org/home/en (accessed on 20 February 2021).

2. Costa, J.M.; Heuvelink, E. The global tomato industry. In Tomatoes; Heuvelink, E., Ed.; CABI: Wallingford, UK, 2018 ; pp. 1-26.

3. Bai, Y.; Lindhout, P. Domestication and Breeding of Tomatoes: What have We Gained and What Can We Gain in the Future? Ann. Bot. 2007, 100, 1085-1094. [CrossRef]

4. Ibáñez, G.; Valcárcel, M.; Cebolla-Cornejo, J.; Roselló, S. FT-MIR determination of taste-related compounds in tomato: A high throughput phenotyping analysis for selection programs. J. Sci. Food Agric. 2019, 99, 5140-5148. [CrossRef] [PubMed]

5. Rodriguez-Saona, L.E.; Aykas, D.P. Tomato Chemistry, Industrial Processing and Product Development; Porretta, S., Ed.; Food Chemistry, Function and Analysis, Royal Society of Chemistry: Cambridge, UK, 2019; ISBN 978-1-78801-396-3.

6. Reuhs, B.L.; Simsek, S. Nuclear Magnetic Resonance. In Food Analysis; Nielsen, S.S., Ed.; Food Science Text Series; Springer: Cham, Switzerland, 2017; ISBN 978-3-319-45774-1.

7. Nicolaï, B.M.; Beullens, K.; Bobelyn, E.; Peirs, A.; Saeys, W.; Theron, K.I.; Lammertyn, J. Nondestructive measurement of fruit and vegetable quality by means of NIR spectroscopy: A review. Postharvest Biol. Technol. 2007, 46, 99-118. [CrossRef]

8. Wang, L.; Sun, D.-W.; Pu, H.; Cheng, J.-H. Quality analysis, classification, and authentication of liquid foods by near-infrared spectroscopy: A review of recent research developments. Crit. Rev. Food Sci. Nutr. 2017, 57, 1524-1538. [CrossRef] [PubMed]

9. Li, Z.-H.; Nie, Y.-F.; Liu, B.; Kuai, Z.-Z.; Zhao, M.; Liu, F. Mechanical properties of AlSi10Mg lattice structures fabricated by selective laser melting. Mater. Des. 2020, 192, 108709. [CrossRef]

10. Crocombe, R.A. Portable Spectroscopy. Appl. Spectrosc. 2018, 72, 1701-1751. [CrossRef]

11. Erfan, M.; Sabry, Y.M.; Sakr, M.; Mortada, B.; Medhat, M.; Khalil, D. On-Chip Micro-Electro-Mechanical System Fourier Transform Infrared (MEMS FT-IR) Spectrometer-Based Gas Sensing. Appl. Spectrosc. 2016, 70, 897-904. [CrossRef]

12. Pérez-marín, D.; Torres, I.; Entrenas, J.; Vega, M.; Sánchez, M. Pre-Harvest Screening on-Vine of Spinach Quality and Safety Using NIRS Technology. Spectrochim. Acta Part A Mol. Biomol. Spectrosc. 2019, 207, 242-250. [CrossRef]

13. Sánchez, M.-T.; De la Haba, M.-J.; Serrano, I.; Pérez-Marín, D. Application of NIRS for Nondestructive Measurement of Quality Parameters in Intact Oranges During On-Tree Ripening and at Harvest. Food Anal. Methods 2012, 6, 826-837. [CrossRef]

14. Marques, E.J.N.; De Freitas, S.T.; Pimentel, M.F.; Pasquini, C. Rapid and non-destructive determination of quality parameters in the 'Tommy Atkins' mango using a novel handheld near infrared spectrometer. Food Chem. 2016, 197, 1207-1214. [CrossRef]

15. Beghi, R.; Spinardi, A.; Bodria, L.; Mignani, I.; Guidetti, R. Apples Nutraceutic Properties Evaluation Through a Visible and Near-Infrared Portable System. Food Bioprocess Technol. 2012, 6, 2547-2554. [CrossRef]

16. Sánchez, M.-T.; De La Haba, M.-J.; Guerrero, J.-E.; Garrido-Varo, A.; Pérez-Marín, D. Testing of a local approach for the prediction of quality parameters in intact nectarines using a portable NIRS instrument. Postharvest Biol. Technol. 2011, 60, 130-135. [CrossRef]

17. Sánchez, M.-T.; De La Haba, M.J.; Benítez-López, M.; Fernández-Novales, J.; Garrido-Varo, A.; Pérez-Marín, D. Non-destructive characterization and quality control of intact strawberries based on NIR spectral data. J. Food Eng. 2012, 110, 102-108. [CrossRef]

18. Pérez-Marín, D.; Paz, P.; Guerrero, J.-E.; Garrido-Varo, A.; Sánchez, M.-T. Miniature handheld NIR sensor for the on-site non-destructive assessment of post-harvest quality and refrigerated storage behavior in plums. J. Food Eng. 2010, 99, 294-302. [CrossRef]

19. Torres, I.; Pérez-Marín, D.; De la Haba, M.-J.; Sánchez, M.-T. Developing universal models for the prediction of physical quality in citrus fruits analysed on-tree using portable NIRS sensors. Biosyst. Eng. 2017, 153, 140-148. [CrossRef] 
20. Liu, Y.; Gao, R.; Hao, Y.; Sun, X.; Ouyang, A. Improvement of Near-Infrared Spectral Calibration Models for Brix Prediction in 'Gannan' Navel Oranges by a Portable Near-Infrared Device. Food Bioprocess Technol. 2010, 5, 1106-1112. [CrossRef]

21. Castrignanò, A.; Buttafuoco, G.; Malegori, C.; Genorini, E.; Iorio, R.; Stipic, M.; Girone, G.; Venezia, A. Assessing the Feasibility of a Miniaturized Near-Infrared Spectrometer in Determining Quality Attributes of San Marzano Tomato. Food Anal. Methods 2019, 12, 1497-1510. [CrossRef]

22. Sánchez, M.-T.; Torres, I.; De La Haba, M.-J.; Chamorro, A.; Garrido-Varo, A.; Pérez-Marín, D. Rapid, simultaneous, and in situ authentication and quality assessment of intact bell peppers using near-infrared spectroscopy technology. J. Sci. Food Agric. 2019, 99, 1613-1622. [CrossRef]

23. Cirilli, M.; Bellincontro, A.; Urbani, S.; Servili, M.; Esposto, S.; Mencarelli, F.; Muleo, R. On-field monitoring of fruit ripening evolution and quality parameters in olive mutants using a portable NIR-AOTF device. Food Chem. 2016, 199, 96-104. [CrossRef]

24. Fernández-Espinosa, A.J. Combining PLS regression with portable NIR spectroscopy to on-line monitor quality parameters in intact olives for determining optimal harvesting time. Talanta 2016, 148, 216-228. [CrossRef]

25. Blakey, R.J. Evaluation of avocado fruit maturity with a portable near-infrared spectrometer. Postharvest Biol. Technol. 2016, 121, 101-105. [CrossRef]

26. Sorak, D.; Herberholz, L.; Iwascek, S.; Altinpinar, S.; Pfeifer, F.; Siesler, H.W. New Developments and Applications of Handheld Raman, Mid-Infrared and Near-Infrared Spectrometers. Appl. Spectrosc. Rev. 2012, 47, 83-115. [CrossRef]

27. Kenda, A.; Frank, A.; Kraft, M.; Tortschanoff, A.; Sandner, T.; Schenk, H.; Scherf, W. Compact High-Speed Spectrometers Based on MEMS Devices with Large Amplitude In-Plane Actuators. Procedia Chem. 2009, 1, 556-559. [CrossRef]

28. USDA. Tomato Grading Visual Aids. Available online: https://www.ams.usda.gov/sites/default/files/media/Tomato_Visual_ Aids\%5B1\%5D.pdf (accessed on 10 December 2015).

29. Wechtersbach, L.; Cigić, B. Reduction of dehydroascorbic acid at low pH. J. Biochem. Biophys. Methods 2007, 70, 767-772. [CrossRef] [PubMed]

30. Akpolat, H.; Barineau, M.; Jackson, K.A.; Aykas, D.P.; Rodriguez-Saona, L.E. Portable Infrared Sensing Technology for Phenotyping Chemical Traits in Fresh Market Tomatoes. Lwt 2020, 124, 109164. [CrossRef]

31. Bertin, N.; Génard, M. Tomato quality as influenced by preharvest factors. Sci. Hortic. 2018, 233, 264-276. [CrossRef]

32. Gilboa, I.L.N.; Shen, E.Y.S.; Schaffer, A.A. Fgr, a Major Locus That Modulates the Fructose to Glucose Ratio in Mature Tomato Fruits. Theor. Appl. Genet. 2000, 100, 256-262.

33. Davies, J.; Hobson, G. The Constituints of Tomato Fruit-The Influence of Environment, Nutrition and Genotype. Food Sci. Nutr. 1981, 15, 205-208.

34. Siddiqui, W.; Chakraborty, I.; Mishra, P.; Hazra, P. Bioactive attributes of tomatoes possessing dg, ogc and rin genes. Food Funct. 2014, 5, 936. [CrossRef]

35. Araus, J.L.; Cairns, J.E. Field high-throughput phenotyping: The new crop breeding frontier. Trends Plant Sci. $2014,19,52-61$. [CrossRef]

36. Beć, K.B.; Grabska, J.; Huck, C.W. Near-Infrared Spectroscopy in Bio-Applications. Molecules 2020, 25, 2948. [CrossRef] [PubMed]

37. Clément, A.; Dorais, M.; Vernon, M. Nondestructive Measurement of Fresh Tomato Lycopene Content and Other Physico-chemical Characteristics Using Visible-NIR Spectroscopy. J. Agric. Food Chem. 2008, 56, 9813-9818. [CrossRef] [PubMed]

38. Flores, K.; Sánchez, M.-T.; Pérez-Marín, D.; Guerrero, J.-E.; Garrido-Varo, A. Feasibility in NIRS instruments for predicting internal quality in intact tomato. J. Food Eng. 2009, 91, 311-318. [CrossRef]

39. Kaur, A.; Donis-Gonzalez, I.R.; Clair, D.A.S. Evaluation of a hand-held spectrophotometer as an in-field phenotyping tool for tomato and pepper fruit quality. Plant Phenome J. 2020, 3, 1-23. [CrossRef]

40. Feng, L.; Zhang, M.; Adhikari, B.; Guo, Z. Nondestructive Detection of Postharvest Quality of Cherry Tomatoes Using a Portable NIR Spectrometer and Chemometric Algorithms. Food Anal. Methods 2019, 12, 914-925. [CrossRef]

41. Pavia, D.L.; Kris, G.S.; Lampman, G.M.; Vyvyan, J.R. Introdução à Espectroscopia; Cengage: Boston, MA, USA, 2010; ISBN 9788522107087.

42. Rodriguez-saona, L.E.; Ayvaz, H.; Wehling, R.L. Infrared and Raman Spectroscopy. In Food Analysis; Nielsen, S.S., Ed.; Springer: Berlin/Heidelberg, Germany, 2017; pp. 107-127, ISBN 978-3-319-45774-1.

43. Osborne, B.G. Near-Infrared Spectroscopy in Food Analysis. Encycl. Anal. Chem. 2000, 1-14. [CrossRef]

44. Bureau, S.; Cozzolino, D.; Clark, C.J. Contributions of Fourier-transform mid infrared (FT-MIR) spectroscopy to the study of fruit and vegetables: A review. Postharvest Biol. Technol. 2019, 148, 1-14. [CrossRef]

45. Wilkerson, E.D.; Anthon, G.E.; Barrett, D.M.; Sayajon, G.F.G.; Santos, A.M.; Rodriguez-Saona, L.E. Rapid Assessment of Quality Parameters in Processing Tomatoes using Hand-Held and Benchtop Infrared Spectrometers and Multivariate Analysis. J. Agric. Food Chem. 2013, 61, 2088-2095. [CrossRef] 